\title{
Mechanical properties of wood/plastic composites formed using wood flour produced by wet ball-milling under various milling times and drying methods
}

\author{
Kazushige Murayama ${ }^{1}$, Takako Ueno ${ }^{1}$, Hikaru Kobori ${ }^{1}$, Yoichi Kojima ${ }^{1 *} \mathbb{0}$, Shigehiko Suzuki ${ }^{1}$, Kenji Aoki ${ }^{1}$, \\ Hirokazu Ito², Shinji Ogoe ${ }^{3}$ and Masaki Okamoto ${ }^{3}$
}

\begin{abstract}
The objective of this study was to investigate the mechanical properties of wood/plastic composites (WPCs) produced using wood flour (WF) prepared by wet ball-milling under various milling times (0-120 min) and drying methods (freeze- or heat drying). The drying method did not affect the particle size distribution, shape, or specific surface area of WF at milling times shorter than 40 min. At milling $\geq 40$ min, freeze-dried ball-milled WF (FDWF) had smaller particle sizes and higher specific surface area than heat-dried ball-milled WF (HDWF). The highest tensile strength and modulus of rupture (MOR) were observed in WPCs made from freeze- and heat-dried WF at a milling time of 30 min. At milling time of 30 min, the amount of 100-300 $\mu \mathrm{m}$ FDWF and HDWF was 37\% and 36\%, respectively. The impact strength of WPCs increased, as the milling time increased. The amount of small freeze- and heat-dried WF particles increased due to an increase in the amount of $17 \mu \mathrm{m}$ particles and specific surface area with increased milling time. Thus, impact strength of WPCs increased as particle size decreased. At milling times $\leq 60 \mathrm{~min}$, there were no significant differences in mechanical properties between WPCs containing freeze- and heat-dried WF under the condition of this study.
\end{abstract}

Keywords: Wood/plastic composites, Wet ball-milling, Drying methods, Mechanical properties, Physical properties

\section{Introduction}

Wood/plastic composites (WPCs) are mixtures of wood flour (WF) and thermoplastic resins, such as polypropylene (PP), polyethylene (PE), or polyvinyl chloride (PVC). WPCs can be fabricated from environmentally friendly materials, such as wood waste, unused natural resources, and recycled thermoplastic resins $[1,2]$. WPCs have many excellent properties such as high durability, specific strength, specific stiffness, and resistance to wear. They also have high molding performance and a texture similar to that of solid wood. The main application of WPCs is in the manufacture of exterior decking. However, for WPC

\footnotetext{
*Correspondence: kojima.yoichi@shizuoka.ac.jp

${ }^{1}$ Faculty of Agriculture, Shizuoka University, 836, Ohya, Suruga-ku,

Shizuoka-Shi, Shizuoka-Shi, Shizuoka-Ken 422-8529, Japan

Full list of author information is available at the end of the article
}

technology continues to mature as manufacturing processes improve, WPCs can also be used in other industries, such as the automobile and consumer electronics sectors $[2,3]$.

WF is among the determinants of the mechanical properties of WPCs. Since WF is hydrophilic, it is necessary to overcome its incompatibility to hydrophobic thermoplastic resins to improve the mechanical properties of WPCs. Physical treatments such as corona, plasma, and ionizing radiation, and chemical treatments such as esterification and acetylation, have been applied to WF to improve compatibility $[4,5]$. However, these treatments require large amounts of energy or the production of considerable hazardous waste. Therefore, small amounts of compatibilizers (e.g., maleic anhydride-grafted polypropylene, MAPP) are generally added to WPC. WF parameters such as particle species, size, and shape are 
also important determinants of the mechanical properties of WPCs. In general, commercial WF with particle sizes of $100-300 \mu \mathrm{m}$ is produced by dry milling by a hammer mill or cutter mill $[1,6,7]$. In a study by Stark and Berger [8], the tensile strengths of WPCs containing oak, maple, and ponderosa pine WF were shown to be similar. In addition, the tensile and flexural strengths of them had the highest value at $20-40 \mathrm{wt} \%$ WF content. In addition, the tensile strength and modulus of rupture (MOR) of WPC containing 235-mesh $(>63 \mu \mathrm{m})$ WF were lower than those of WPC containing 70-mesh $(>185 \mu \mathrm{m})$ WF. Salemane and Luyt [9] reported that the tensile strength of WPCs containing WF with particle size $<38 \mu \mathrm{m}$ was lower than that of WPCs containing WF with particle sizes of 38-150 $\mu \mathrm{m}$ and $300-600 \mu \mathrm{m}$. In addition, in the case of same size filler, Stark and Rowlands [10] reported that WPCs containing high aspect ratio filler had higher mechanical properties than that containing low aspect ratio filler.

WF formed by ball-milling is also used to produce WPCs [11-13]. The tensile and flexural strengths of WPCs containing wet ball-milling WF had high strength by surface fibrous structure on WF $[11,12]$. The strength did not improve in the WPCs containing dry ball-milling WF [13]. Thus, the size and shape of WF prepared by wet ball-milling effectively improve the mechanical properties of WPCs. However, the mechanical properties of WPCs containing WF that had been wet ball-milled shorter than $2 \mathrm{~h}$ were not evaluated.

Therefore, the objective of this study was to investigate the effect of size and shape of WF wet ball-milling at times shorter than or equal to $2 \mathrm{~h}$ on the mechanical properties of WPCs.

In the previous studies, milled WF was vacuum- and freeze-dried [11-13]. During heat drying, WF becomes easily aggregated through rapid water vaporization. However, it has been assumed that WF aggregation during heat drying is negligible with short milling times. Therefore, we also evaluated the effect of the drying method on ball-milled WF (BMWF) in this study.

\section{Materials and methods Materials}

The raw material for this study was Japanese red pine (Pinus densiflora) WF with a particle size of about $2 \mathrm{~mm}$. PP (J-107G; Prime Polymer Co. Ltd., Japan) as a matrix was a homopolymer with a melt flow rate of $30 \mathrm{~g} / 10 \mathrm{~min}$ $\left(230{ }^{\circ} \mathrm{C} / 2.16 \mathrm{~kg}\right)$ and a density of $0.9 \mathrm{~g} / \mathrm{cm}^{3}$. MAPP (Kayabrid 006PP-N; Kayaku Akzo Co. Ltd., Japan) as a compatibilizer were used. The MAPP powder contained $2 \mathrm{wt} \%$ maleic anhydride and had an average molecular weight of 75,000 .

\section{Preparation of wood flour}

Ball-milling was performed using a planetary ball mill (Pulverisette 6; Fritsch Japan Co., Ltd., Japan). For each load, WF (13.5 g) and distilled water $(200 \mathrm{~mL})$ were milled with 25 balls (diameter: $20 \mathrm{~mm}$ ) in a cycle consisting of $10 \mathrm{~min}$ of milling, followed by a $10 \mathrm{~min}$ pause, for the prescribed time. This step was the same as previous study [12]. The ball-milling rotational speed was set to $200 \mathrm{rpm}$ and the milling times were $0,10,20,30,40$, 60 , and $120 \mathrm{~min}$. The BMWF was dried under two types of drying processes: heat drying and freeze-drying. The conditions for freeze-drying were $-45{ }^{\circ} \mathrm{C}$ for $168 \mathrm{~h}$ in a freeze-dryer (FDD1200; Tokyo Rikakikai Co. Ltd., Japan). The conditions for heat drying were $80^{\circ} \mathrm{C}$ for $24 \mathrm{~h}$ in an oven dryer (SOFW-600; AS ONE Co. Ltd., Japan). The BMWF after drying was crushed using a mixer (IFM800DG; Iwatani Co. Ltd., Japan). The products of these processes were termed freeze-dried BMWF (FDWF) and heat-dried BMWF (HDWF), respectively.

\section{Wood flour characteristics}

A laser-diffraction particle size distribution analyzer (Partica LA-9502; Horiba Ltd., Japan) was used to obtain the particle size distributions of BMWF, FDWF, and HDWF. FDWF and HDWF surface morphology was observed using a scanning electron microscope (SEM) (JSM-6510LV2; JEOL Ltd., Japan). FDWF- and HDWFspecific surface area (Brunauer-Emmett-Teller area) was measured using the nitrogen adsorption method with a specific surface area and pore size distribution analyzer (Gemini 2360BELSORP-mini II,; MicrotracBEL Ltd., Japan). Prior to measurements, WF was dried at $105{ }^{\circ} \mathrm{C}$ for $6 \mathrm{~h}$ under a flow of $\mathrm{N}_{2}$.

\section{Preparation of WPCs}

The materials were blended at a dried BMWF/MAPP/PP ratio of $25 / 1 / 74$ (wt\%). The WF content was lower than general WPC products to avoid interaction WF itself. Compounds of dried BMWF/MAPP/PP were produced at $190{ }^{\circ} \mathrm{C}$ for $13 \mathrm{~min}$ at a rotary speed of $30 \mathrm{rpm}$ using a twin-screw kneader (Laboplast Mill 30R150; Toyo Seiki Seisaku-sho Ltd., Japan). The compounds were crushed using a low speed axial crusher (SA-23; Stolz Co. Ltd., Japan) into a powder with particle size $<10 \mathrm{~mm}$. The crushed compounds were then melted and mixed using a micro-compounder (Micro5 cc Twin-Screw Compounder; DSM Xplore, The Netherlands) at $190{ }^{\circ} \mathrm{C}$ for $5 \mathrm{~min}$ at a rotary speed of $50 \mathrm{rpm}$. An injection molder (Micro5.5 cc Injection Molding Machine; DSM Xplore, The Netherlands) was then used to mold the composites into two types of specimens at $190{ }^{\circ} \mathrm{C}$, with an injection pressure of 1.6 $\mathrm{MPa}$. The dimensions of dumbbell-shaped 
specimens produced for the subsequent tensile test were about $50 \times 4 \times 2 \mathrm{~mm}$, and those of rectangular specimens produced for bending and impact tests were about $50 \times 6 \times 2 \mathrm{~mm}$. All specimens were stored at $20{ }^{\circ} \mathrm{C}$ and $65 \%$ relative humidity for 1 week before each test. The moisture content of all WPC specimens was about $0.5 \%$.

\section{Mechanical properties of WPCs}

WPC performance was evaluated by tensile, bending, and impact tests. The tensile and bending tests were conducted according to the JIS A-5741 protocol [14]. Tensile strength was tested using a universal testing machine (AGS-5kNX; Shimadzu Co. Ltd., Japan) with a crosshead speed of $20 \mathrm{~mm} / \mathrm{min}$ and a gauge length of $30 \mathrm{~mm}$. A three-point bending strength test was conducted to calculate the MOR and modulus of elasticity (MOE) using a universal testing machine (Yasui Kiki Co. Ltd., Japan) with a crosshead speed of $5 \mathrm{~mm} / \mathrm{min}$ and a span length of $32 \mathrm{~mm}$. An unnotched Izod impact test was conducted according to the JIS K-7110 protocol [15] using an impact tester (U-F impact tester; Ueshima Seisaku-sho, Japan) at a speed of $3.5 \mathrm{~m} / \mathrm{s}$ and impact energy of 2 J. Five specimens were tested for each mechanical test. SEM was used to observe the broken surfaces of WPCs after tensile testing at milling times of 0 and $30 \mathrm{~min}$.

\section{Results and discussion}

\section{Evaluation of wood flour}

Particle size distributions for all the types of WF and all milling times are shown in Fig. 1. BMWF and FDWF particle sizes decreased as milling time increased (Fig. 1a, b). However, the HDWF particle size distributions for milling times of 40 and 60 min were almost the same (Fig. 1c). HDWF particle sizes could not be measured for the 120 min milling time due to the production of particles too large to measure by the laser-diffraction particle size distribution analyzer. The frequency of about $1.0 \mathrm{~mm}$ particles at 0 min of milling was higher for HDWF than FDWF; however, the particle size distributions were almost the same for both drying methods (Fig. 1b, c). At milling times at 10-30 min, there were no significant differences between the particle size distributions of FDWF and HDWF. At milling times longer than or equal to 40 min, FDWF produced smaller particles than HDWF. The frequency of $17 \mu \mathrm{m}$ particles was lower for HDWF than FDWF. The relationship between the frequency of $17 \mu \mathrm{m}$ particles and milling time is shown in Fig. 2. The amount of $17 \mu \mathrm{m}$ particles increased for both FDWF and HDWF as milling time increased. At milling times longer than or equal to $40 \mathrm{~min}$, the amount of $17 \mu \mathrm{m}$ particles of HDWF was lower than these of FDWF. At a milling time of $60 \mathrm{~min}$, the amount of $17 \mu \mathrm{m}$ particles of HDWF was 0.56 times of FDWF. Therefore, $17 \mu \mathrm{m}$ particles from
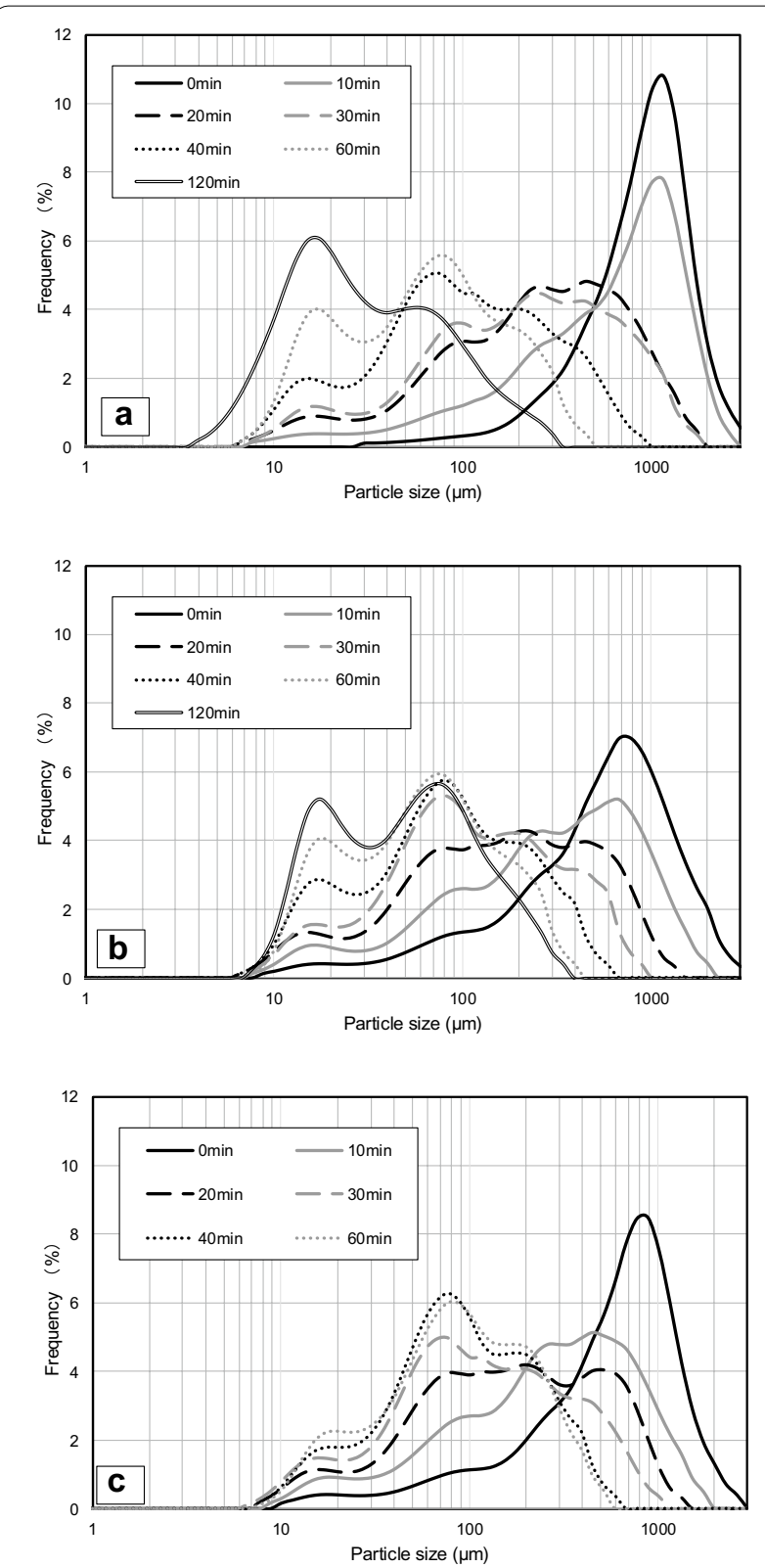

Fig. 1 Particle-size distributions of wet ball-milled wood flour (WF) a before drying (BMWF), $\mathbf{b}$ after freeze-drying (FDWF), and $\mathbf{c}$ after heat drying (HDWF) at different milling times

BMWF aggregated easily by heat drying. However, it is thought that increases of small size WF amount and WF aggregation occurred same time by heat drying, because $17 \mu \mathrm{m}$ particles still increases at a milling time $60 \mathrm{~min}$.

Figure 3 shows the relationship between milling time and the cumulative frequency of particles from 100 to $300 \mu \mathrm{m}$, which are considered to be of optimum size for use in WPCs $[1,6,7]$. At milling times shorter than $40 \mathrm{~min}$, the amount of FDWF particles at $100-300 \mu \mathrm{m}$ increased, and then decreased, as milling time increased. 


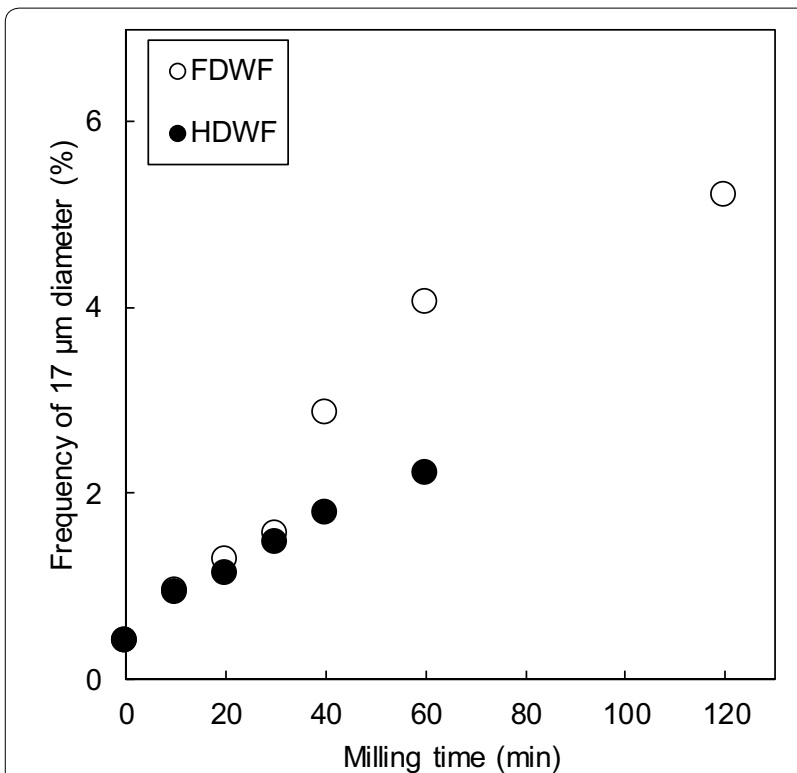

Fig. 2 Relationship between milling time and the frequency of $17 \mu \mathrm{m}$ dried BMWF (FDWF and HDWF)

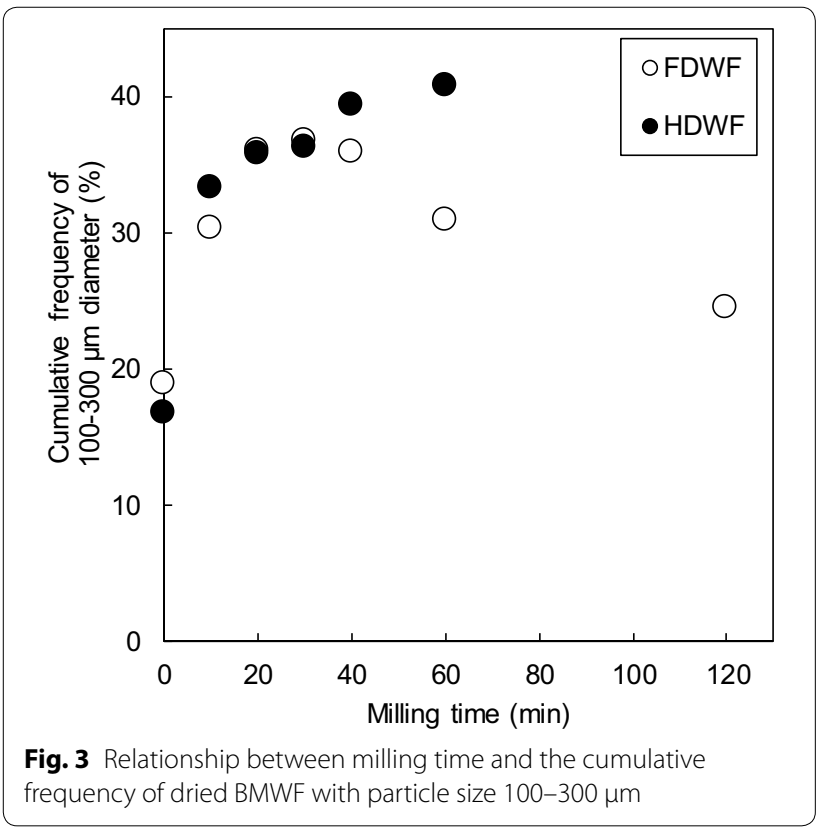

In contrast, the amount of HDWF particles at 100$300 \mu \mathrm{m}$ increased as milling time increased. At milling times of 40 and $60 \mathrm{~min}$, there was 1.1 and 1.3 times more 100-300 $\mu \mathrm{m}$ particles from HDWF than FDWF. These results suggest that the number of HDWF particles at 100-300 $\mu \mathrm{m}$ increased through WF aggregation.

SEM images of FDWF and HDWF produced at different milling times are shown in Figs. 4, 5. At milling times shorter than $40 \mathrm{~min}$, there were no significant differences in WF shape between FDWF and HDWF (Fig. 4a-h). A similar trend was observed in particle sizes (Figs. 2, 3). Although particle size distributions differed according to drying method at a milling time of $40 \mathrm{~min}$, SEM images did not show a difference in WF shape between FDWF and HDWF (Fig. 5a, b). In FDWF particles produced at a milling time of $60 \mathrm{~min}$, many fibrous structures were observed on the WF surface (Fig. 5c). In contrast, in HDWF particles produced at a milling time of $60 \mathrm{~min}$, WF aggregates were observed (Fig. 5d). These aggregates may have been caused by the smaller particle diameter of $17 \mu \mathrm{m}$ (Fig. 2). At a milling time of $120 \mathrm{~min}$, FDWF progressed to fibrillization and HDWF formed large WF aggregates (Fig. 5e, f).

Figure 6 shows the relationship between specific surface area and milling time in FDWF and HDWF. In both FDWF and HDWF, the specific surface area increased as milling time increased. As the specific surface area of particles increased, particle size decreased. These results were consistent with the particle size results, as shown in Fig. 2. There were no significant differences in specific surface area between FDWF and HDWF at milling times shorter than $40 \mathrm{~min}$. At milling times longer than or equal to $40 \mathrm{~min}$, FDWF particles had a higher specific surface area than those of HDWF. At a milling time of $120 \mathrm{~min}$, the specific surface area of FDWF particles was three times larger than that of HDWF.

In total, 14 types of FDWF and HDWF under different milling times and drying methods were prepared in this study. However, we could not measure the particle size distribution of HDWF at a milling time of $120 \mathrm{~min}$. Therefore, we will not discuss the mechanical properties of WPCs containing FDWF and HDWF produced at a milling time of $120 \mathrm{~min}$.

\section{Mechanical properties of WPCs}

Figure 7 shows the relationship between tensile strength of WPCs and milling time. At milling times shorter than $40 \mathrm{~min}$, the tensile strength of WPCs increased as milling time increased. At a milling time of $30 \mathrm{~min}$, the highest tensile strength was observed for both FDWF and HDWF. Specific surface area and particle size of both FDWF and HDWF were almost same at milling time of 30 min; specific surface area of both FDWF and HDWF was 1.8 and $1.6 \mathrm{~m}^{2} / \mathrm{g}$, respectively (Fig. 6), and the amount of 100-300 $\mu \mathrm{m}$ FDWF and HDWF was $37 \%$ and 36\%, respectively (Fig. 3). In SEM images, fibrous structures on the WF surface were not remarkably observed at milling time of $30 \mathrm{~min}$ (Fig. $4 \mathrm{~g}, \mathrm{~h}$ ). In addition, there were no significant differences in WF shape between FDWF and HDWF at milling time of shorter than $60 \mathrm{~min}$. Therefore, it is thought that the effect of particle sizes of WF is higher than that of shapes of WF for tensile strength of 

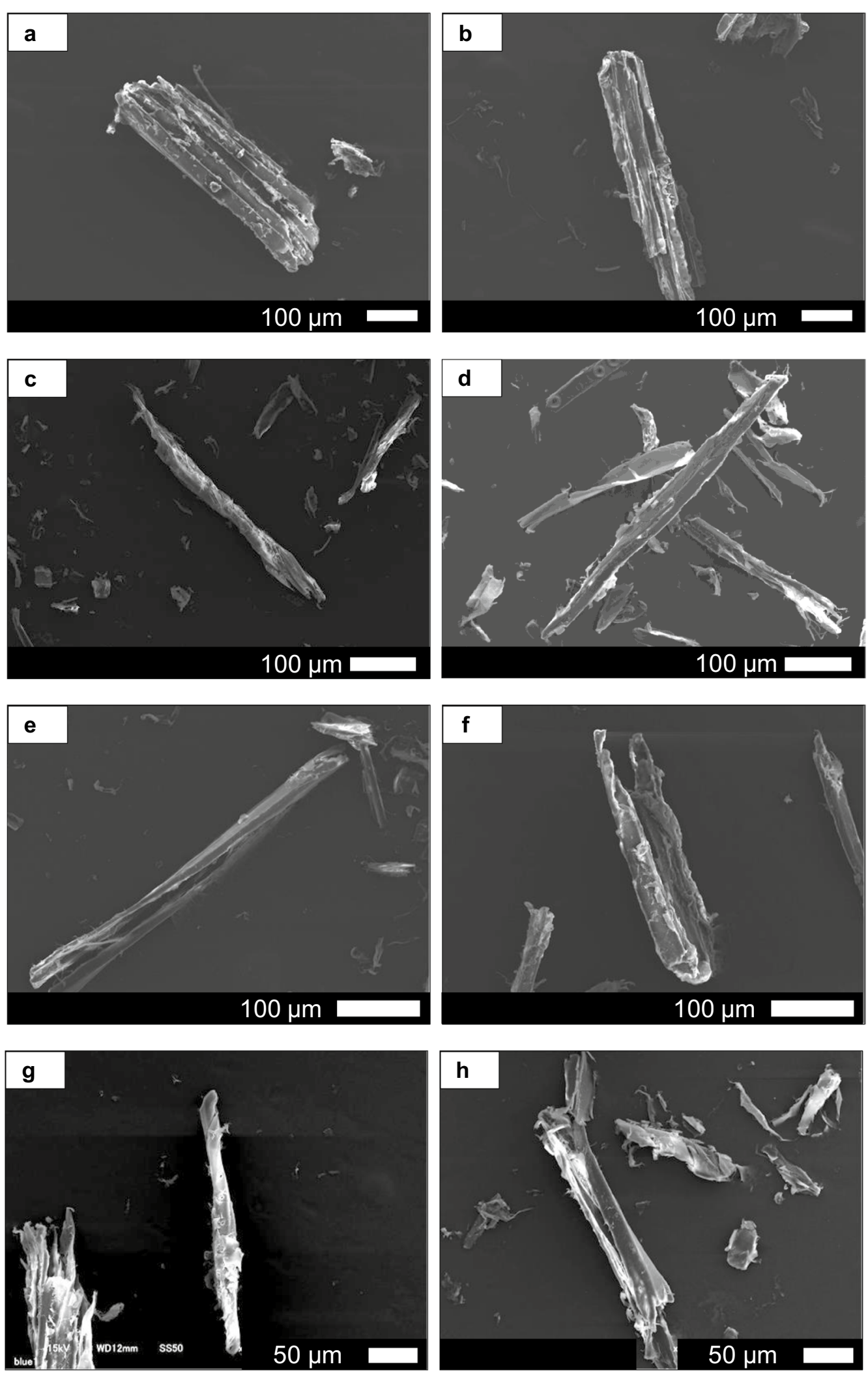

Fig. 4 SEM images of FDWF at milling times of a 0 min, c $10 \mathrm{~min}, \mathbf{e} 20 \mathrm{~min}$, and $\mathbf{g} 30 \mathrm{~min}$; and of HDWF at milling times of $\mathbf{b} 0 \mathrm{~min}, \mathbf{d} 10 \mathrm{~min}, \mathbf{f}$ $20 \mathrm{~min}$, and $\mathbf{h} 30 \mathrm{~min}$ 

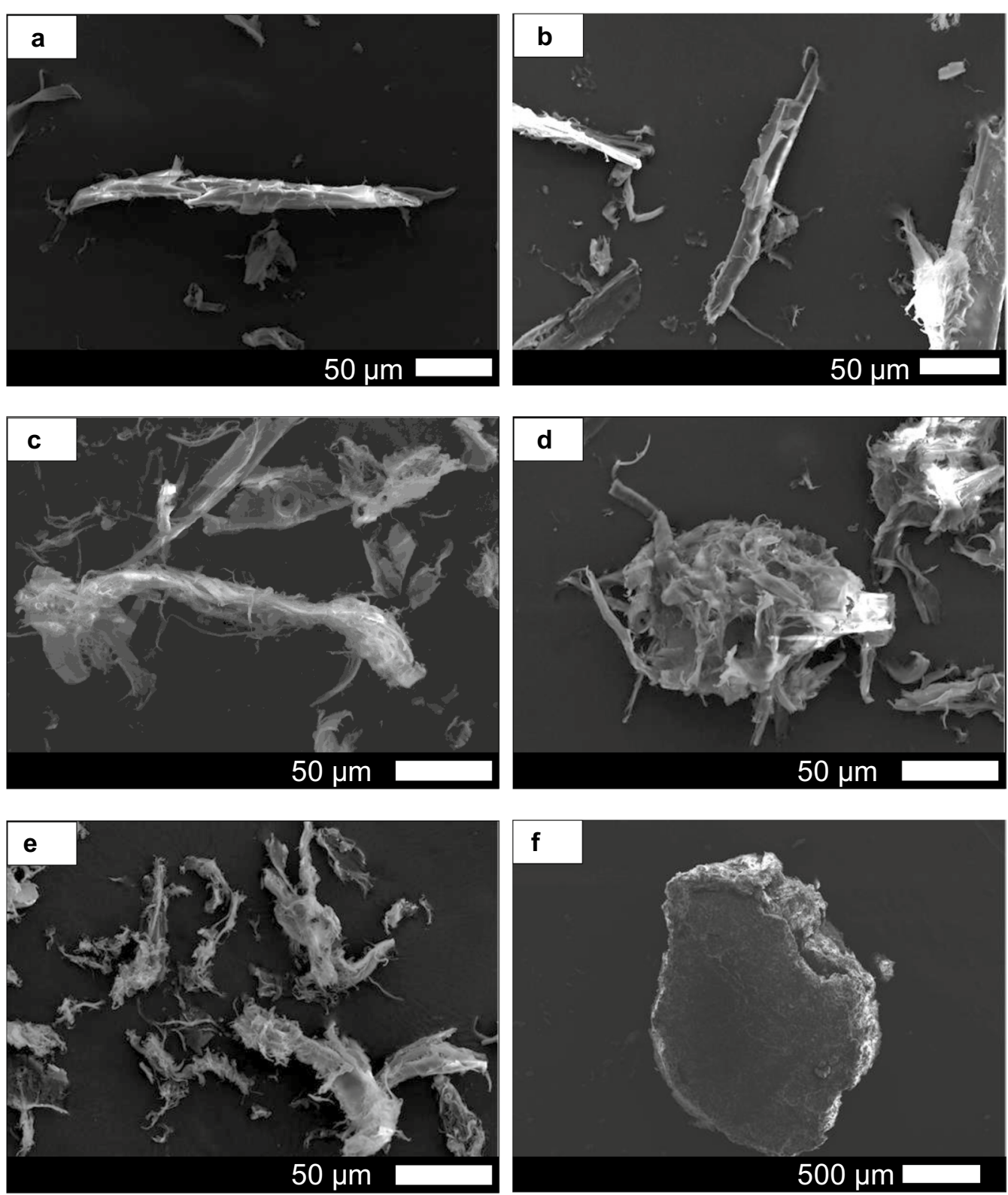

Fig. 5 SEM images of FDWF at milling times of a $40 \mathrm{~min}, \mathbf{c} 60 \mathrm{~min}$, and $\mathbf{e} 120 \mathrm{~min}$; and of HDWF at milling times of $\mathbf{b} 40 \mathrm{~min}$, $\mathbf{d} 60 \mathrm{~min}$, and $\mathbf{f}$ $120 \mathrm{~min}$

WPCs in this study. Figure 8 shows SEM images of the broken surfaces of tensile specimens produced at milling times of 0 min, $30 \mathrm{~min}$, and $60 \mathrm{~min}$. Many fibrous structures were observed on these broken surfaces in particles produced after 30 min of milling (Fig. 8c, d), possibly due to reinforcement between WF and the matrix. The SEM results demonstrate the improved tensile strengths of WPCs. At milling times longer than or equal to $40 \mathrm{~min}$, tensile strength of WPCs decreased as milling time increased. At milling time of $60 \mathrm{~min}$, many fibrous structures of WF were shown by FDWF (Fig. 5c, d). The previous research reported that WPCs containing WF on fibrous structure had higher strength than that without fibrous structure [12]. However, the tensile strength of WPCs with 60 min milling time FDWF was lower than that with 30 min milling time FDWF which did not have fibrous structure. More fibrous structures were observed on the broken surface in particles produced after $60 \mathrm{~min}$ of milling compared to $30 \mathrm{~min}$ of milling (Fig. 8c, e), possibly due to reinforcement 


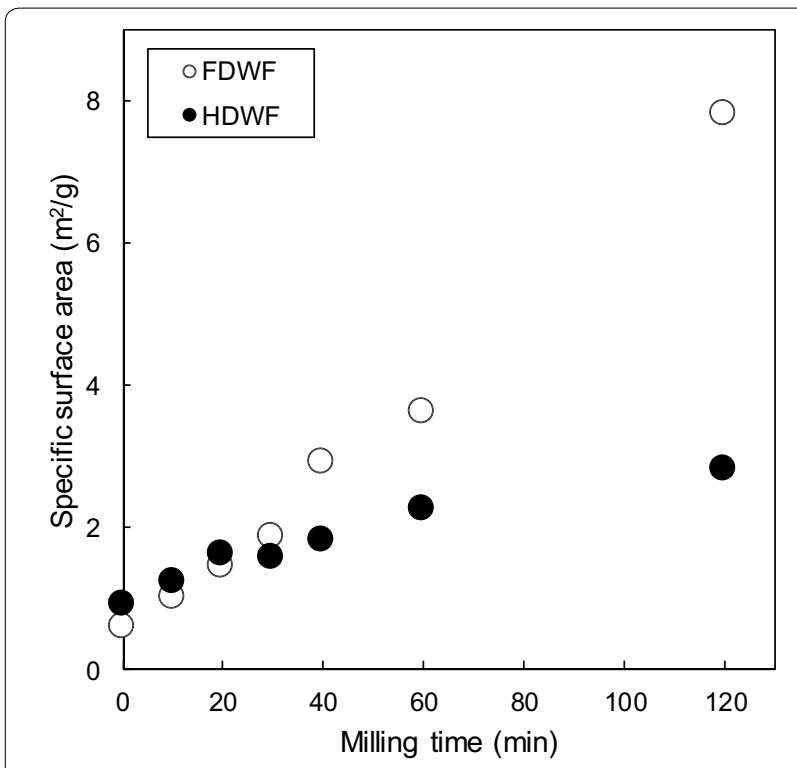

Fig. 6 Relationship between milling time and specific surface area of dried BMWF

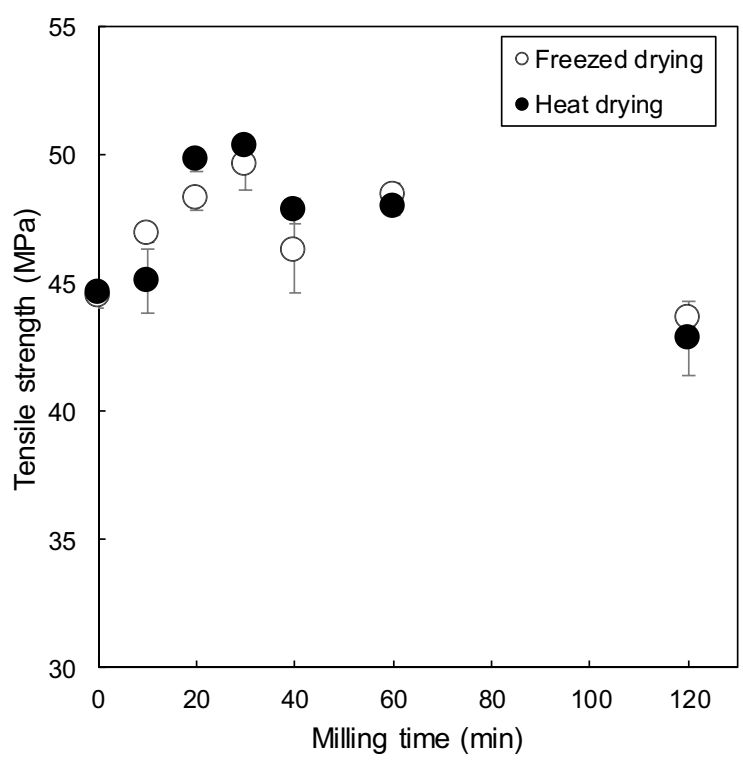

Fig. 7 Relationship between milling time and tensile strength of WPC. Vertical bars indicate standard deviations

between WF and the matrix. Therefore, it is thought that the reinforcement between FDWF and PP is stronger at 60 min of milling. On the other hand, the broken surface of WPC with 60 min milling time FDWF had smaller particle than that with 30 min milling time FDWF. Under this condition, these results suggest that the particle size of WF had higher influence for tensile strength of WPCs than fibrous structure of WF. In addition, at milling times longer than or equal to $40 \mathrm{~min}$, there were no significant differences in tensile strength between WPCs containing FDWF and HDWF under same milling time. After 40 min milling time, it was obvious that the particle size of FDWF and HDWF was different under same milling time (Figs. 2 and 3). In the SEM images of the broken surface at milling time of $60 \mathrm{~min}$, fibrous structure on WPC with HDWF was remarkably smaller amount than that with FDWF (Fig. 8e, f). Thus, it is thought that the reinforcement between WF and PP was also changed under different drying methods at milling times longer or equal than $40 \mathrm{~min}$. However, differences in WF size and shape as a result of the drying method did not influence tensile strength of WPC. In WPCs made with FDWF, trends in tensile strength behavior were similar to trends in the behavior of 100-300 $\mu \mathrm{m}$ particles (Fig. 3). For 100 $300 \mu \mathrm{m}$ particles, WF particle size is likely to have an important influence on mechanical properties of WPCs. At milling times of 40 and $60 \mathrm{~min}$, the tensile strength of WPCs containing HDWF decreased; however, the amount of 100-300 $\mu \mathrm{m}$ HDWF particles increased. At milling times of 40 and $60 \mathrm{~min}, 100-300 \mu \mathrm{m}$ HDWF particles appeared to increase through WF aggregation. Therefore, 100-300 $\mu \mathrm{m}$ HDWF particles derived from aggregated WF would not contribute to tensile strength of WPC.

Figure 9 shows the relationship between milling time and bending properties, MOR and MOE. At a milling time of $30 \mathrm{~min}$, the highest MOR among WPCs was observed in both FDWF and HDWF (Fig. 9a). At milling times of 10 and $40 \mathrm{~min}$, the MOR of WPCs containing HDWF was smaller than that of WPCs containing FDWF. However, at other milling times, there were no differences in MOR between WPCs containing FDWF and HDWF. There were no clear relationships between MOR of WPCs and WF size or shape for either drying method. These trends are similar to tensile strength of WPCs (Fig. 7). MOE of WPCs was not affected by milling time or drying method, except at milling times of 10 and $20 \mathrm{~min}$ (Fig. 9b). In this study, different milling times affected the tensile strength and MOR of WPCs formed with both FDWF and HDWF; however, the MOE of WPCs was not affected.

Figure 10 shows the relationship between the unnotched Izod impact strength of WPCs and milling time. The impact strength of WPCs increased as milling time increased. This trend differed from that of tensile strength and MOR in WPCs. The unnotched Izod impact strength of WPCs decreased, as the filler size increased or filler aspect ratio decreased $[8,9]$. The amount of small HDWF particles increased due to an increase in the amount of $17 \mu \mathrm{m}$ particles and specific surface area 

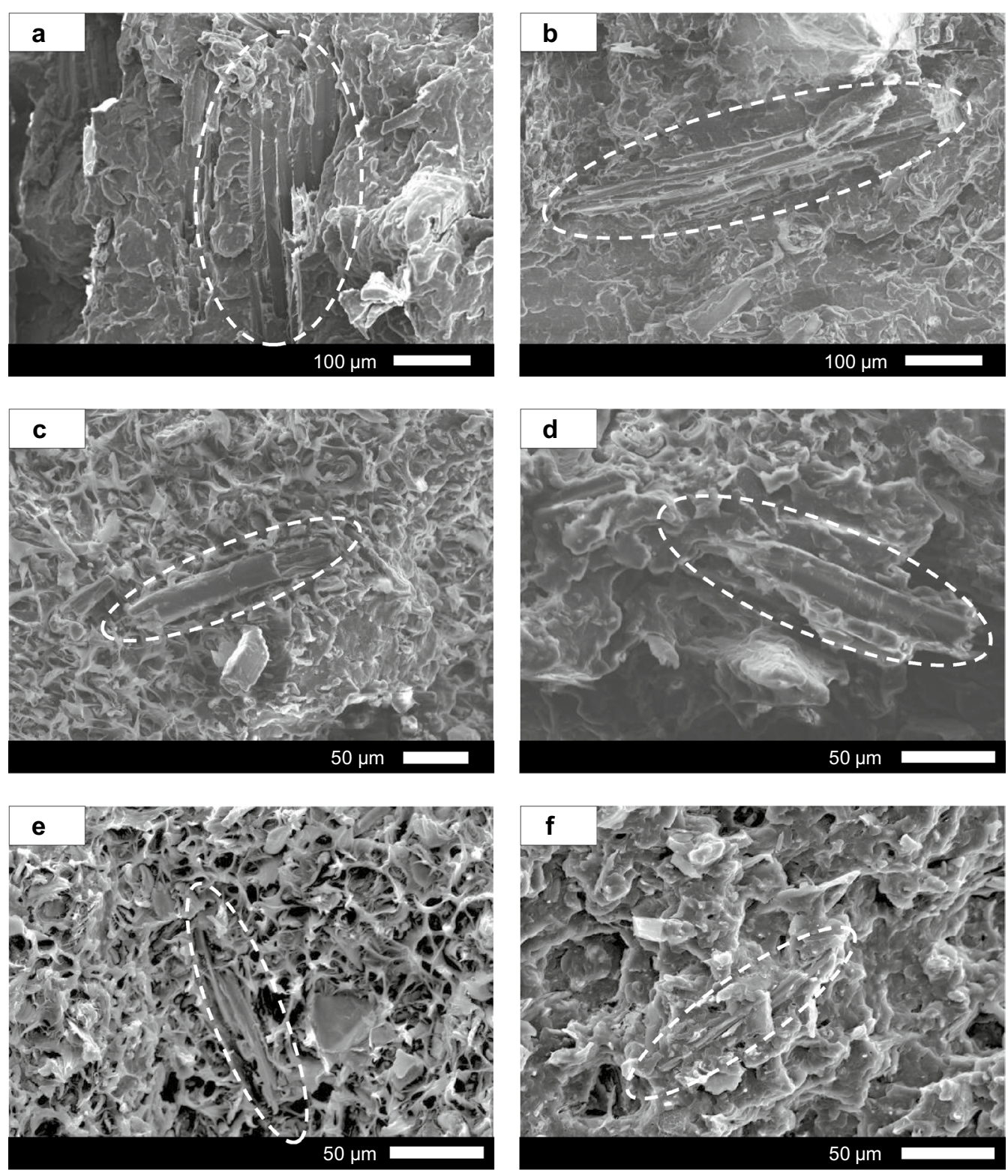

Fig. 8 SEM images of broken surfaces of tensile WPC specimens containing FDWF produced at milling times of a 0 min, c 30 min, and e 60 min; and HDWF produced at milling times of $\mathbf{b} 0 \mathrm{~min}, \mathbf{d} 30 \mathrm{~min}$, and $60 \mathrm{~min}$

with increased milling time (Figs. 2, 4, 5). Thus, impact strength of WPCs increased, as particle size decreased. In addition, drying methods of BMWF did not influence impact strength of WPC. This trend was consistent with that of the tensile and bending properties. HDWF particles sized 100-300 $\mu \mathrm{m}$ derived from aggregated WF did not contribute to impact strength, tensile strength, or MOR

The differences in WF size and shape due to different drying methods did not affect mechanical properties in this study. There are the possibility that size and shape of FDWF and HDWF inside WPCs did not larger differ at same milling time because of defibration of aggregated HDWF or inversely the aggregation of small size FDWF during mixing and molding for WPCs. It will be proven by measuring size and shape of WF inside WPCs. This is a matter for future investigation. However, it is a significant finding that WPCs containing HDWF have the same mechanical properties as those containing FDWF under the condition of this study, 

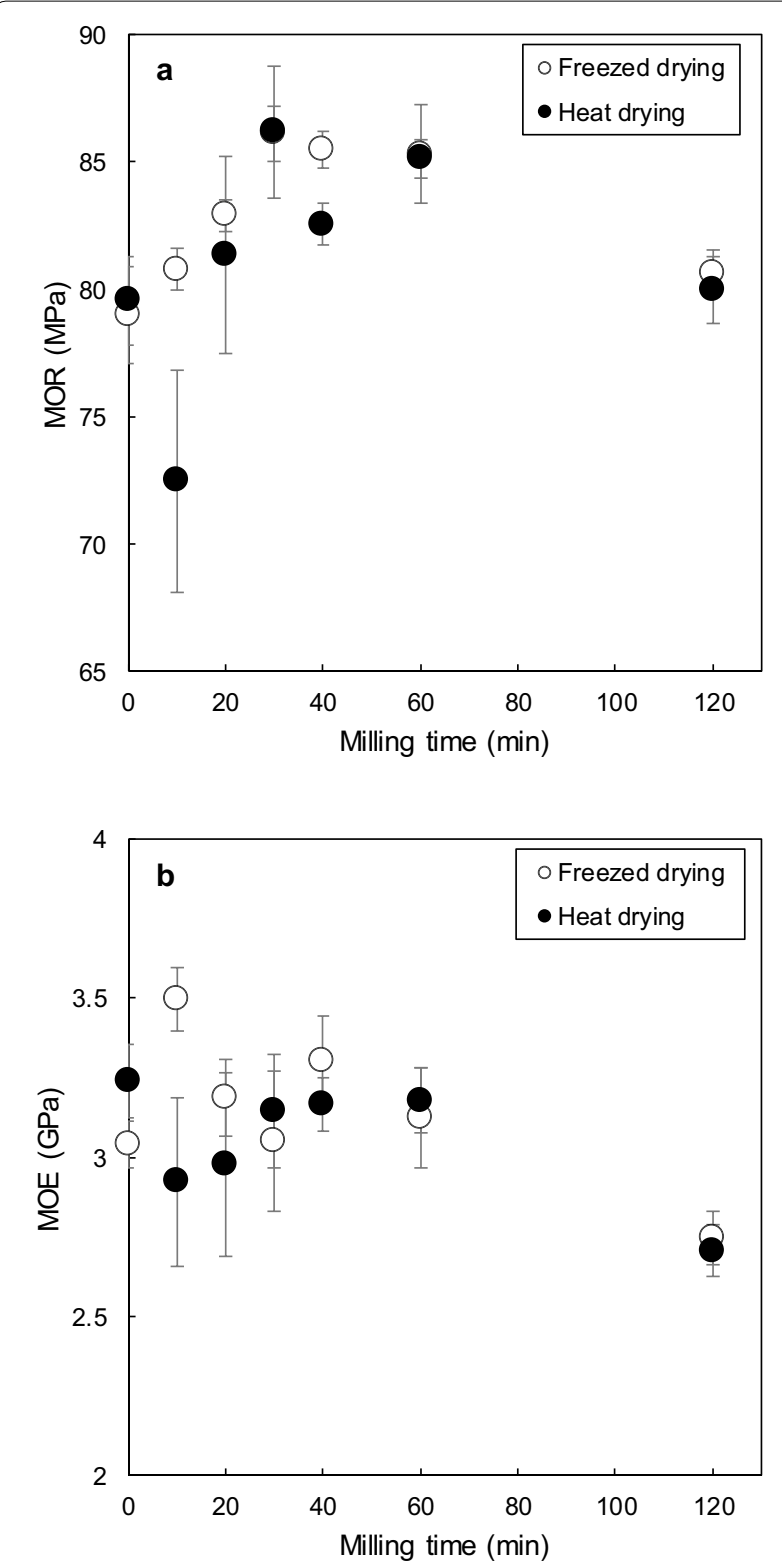

Fig. 9 Relationship between milling time and $\mathbf{a} M O R$ and $\mathbf{b}$ MOE of WPC. Vertical bars indicate standard deviations

because heat drying requires less energy and shorter drying times than freeze-drying.

\section{Conclusion}

The objective of this study was to investigate the effect of WF produced by short wet-milling times and two different drying methods on the mechanical properties of WPCs. WF were prepared by wet ball-milling for 0-120 min followed by freeze- or heat drying. Tensile,

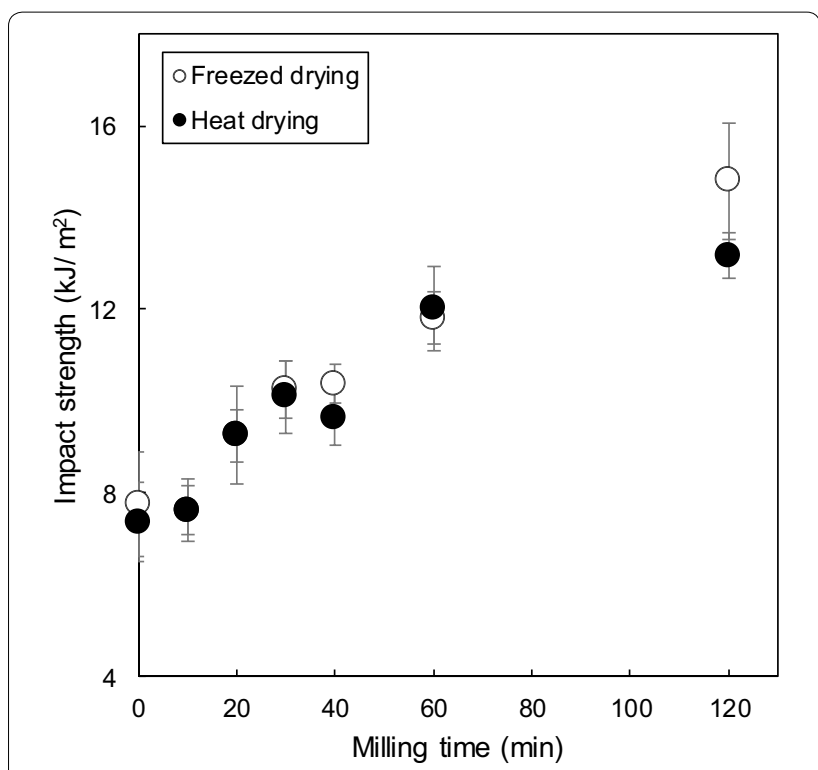

Fig. 10 Relationship between milling time and impact strength of WPC. Vertical bars indicate standard deviations

bending, and impact properties of WPCs formed from these WF were evaluated. The main results of this study are summarized as follows:

1. The drying method did not affect the particle size distribution, shape, or specific surface area of WF at milling times shorter than $40 \mathrm{~min}$. At milling times longer than or equal to $40 \mathrm{~min}$, FDWF particles were smaller and had higher specific surface area than HDWF particles.

2. The highest tensile strength and MOR among WPCs were observed for both FDWF and HDWF at a milling time of $30 \mathrm{~min}$. In the case of FDWF, trends in tensile strength were consistent with trends in 100$300 \mu \mathrm{m}$ particle size behavior.

3. Impact strength of WPC increased as milling time increased, possibly due to an increase in the amount of small WF particles.

4. At milling times shorter than or equal to $60 \mathrm{~min}$, there were no significant differences in the mechanical properties of WPCs containing FDWF and HDWF. Different drying methods did not affect mechanical properties of WPCs under the condition of this study.

\section{Abbreviations}

WPC: wood/plastic composite; WF: wood flour; PP: polypropylene; PE: polyethylene; PVC: polyvinyl chloride; MAPP: maleic anhydride-grafted polypropylene; 
BMWF: ball-milled WF; FDWF: freeze-dried ball-milled wood flour; HDWF: heat-dried ball-milled wood flour; SEM: scanning electron microscope; MOR: modulus of rupture; MOE: modulus of elasticity.

\section{Authors' contributions}

$\mathrm{KM}, \mathrm{TU}$, and YK have participated sufficiently in the work to take public responsibility for entire of the content of the manuscript. HK, SS, KA, HI, SO, and $\mathrm{MO}$ have participated sufficiently in the work to take public responsibility for part of the content of the manuscript. All authors read and approved the final manuscript.

\section{Author details}

1 Faculty of Agriculture, Shizuoka University, 836, Ohya, Suruga-ku, Shizuoka-Shi, Shizuoka-Shi, Shizuoka-Ken 422-8529, Japan. ${ }^{2}$ National Institute of Advanced Industrial Science and Technology, 3-11-32, Kagami-yama, Higashi-hiroshima-Shi, Hiroshima-Ken 739-0046, Japan. ${ }^{3}$ Toclas Corporation, 1370, Nishiyama-cho, Nishi-ku, Hamamatu-Shi, Shizuoka-Ken 423-8001, Japan.

\section{Acknowledgements}

Nothing.

\section{Competing interests}

The authors declare that they have no competing interests.

Availability of data and materials

Not applicable.

\section{Funding}

Nothing.

\section{Publisher's Note}

Springer Nature remains neutral with regard to jurisdictional claims in published maps and institutional affiliations.

Received: 3 October 2018 Accepted: 3 February 2019

Published online: 13 February 2019

\section{References}

1. Moreno PDD, Saron C (2017) Low-density polyethylene waste/recycled wood composites. Compos Struct 176:1152-1157
2. Kim JK, Pal K (2010) Recent advances in the processing of wood-plastic composites. Springer, Berlin, pp 23-25

3. Gardner JD, Han Y, Wang L (2015) Wood-plastic composite technology. Curr For Rep 1(3):139-150

4. Wei L, McDonald GA, Freitag C, Morrell JJ (2013) Effects of wood fiber esterification on properties, weatherability and biodurability of wood plastic composites. Polym Degrad Stab 98(7):1348-1361

5. Palm A, Smith J, Driscoll M, Smith L, Larsen SL (2016) Chemical constituent influence on ionizing radiation treatment of a wood-plastic composite. Radiat Phys Chem 124:164-168

6. Watanabe A (2012) Wood-plastic composites update-for recycling wood resources - part I: history, current status, and future prospects of woodplastic composites (in Japanese). Wood Ind 67(11):466-469

7. Ito H (2010) Utilization wood fiber for wood-plastic composites of high filler content (in Japanese). J Soc Mater Sci 59(4):259-267

8. Stark MN, Berger MJ (1997) Effect of species and particle-size on properties of wood-flour-filled polypropylene composites. In: Proceedings of functional fillers for thermoplastic and thermosets, INTERTECH/USA, Conference, California, 8-10 December 1997

9. Salemane GM, Luyt SA (2006) Thermal and mechanical properties of polypropylene-wood powder composites. J Appl Polym Sci 100(5):4173-4180

10. Stark MN, Rowlands ER (2003) Effects of wood fiber characteristics on mechanical properties of wood/polypropylene composites. Wood Fiber Sci 35(2):167-174

11. Isa A, Minamino J, Mizuno H, Suzuki S, Kojima Y, Ito H, Makise R, Okamoto $M$, Hasegawa $T$ (2013) Increased water resistance of bamboo flour/polyethylene composites. J Wood Chem Technol 33(3):208-216

12. Isa A, Toyoda T, Suzuki S, Kojima Y, Ito H, Makise R, Okamoto M (2014) The effects of wet-milled wood flour on the mechanical properties of wood flour/polypropylene composites. J Wood Chem Technol 34(1):20-30

13. Isa A, Minamino J, Kojima Y, Suzuki S, Ito H, Makise R, Okamoto M, Endo T (2016) The influence of dry-milled wood flour on the physical properties of wood flour/polypropylene composites. J Wood Chem Technol 36(2):105-113

14. JIS A5741-2016 (2016) Wood-plastic recycled composite (in Japanese). Japanese Standards Association, Tokyo, pp 1172-1191

15. JIS K7110-1984 (1999) Plastics determination of Izod impact strength (in Japanese). Japanese Standards Association, Tokyo, pp 317-334

\section{Submit your manuscript to a SpringerOpen ${ }^{\circ}$ journal and benefit from:}

- Convenient online submission

- Rigorous peer review

- Open access: articles freely available online

- High visibility within the field

- Retaining the copyright to your article

Submit your next manuscript at $\boldsymbol{\nabla}$ springeropen.com 